\title{
Correction to: Serum vitamin D, vitamin D receptor and binding protein genes polymorphisms in restless legs syndrome
}

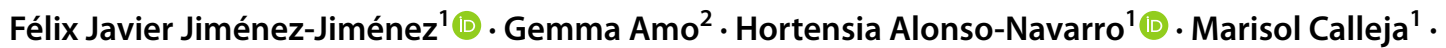
Mónica Díez-Fairén ${ }^{3,4}$. Ignacio Alvarez $z^{3,4}$ (1) Pau Pastor ${ }^{3,4}$. José Francisco Plaza-Nieto ${ }^{1}$. Santiago Navarro-Muñoz ${ }^{5}$. Laura Turpín-Fenoll $^{5}$. Jorge Millán-Pascual ${ }^{5} \cdot$ Marta Recio-Bermejo $^{5} \cdot$ Rafael García-Ruiz $^{5}$ - Esteban García-Albea ${ }^{6}$. José A. G. Agúndez ${ }^{2}$ - Elena García-Martín ${ }^{2} \mathbb{D}$

Published online: 19 February 2021

(c) Springer-Verlag GmbH Germany, part of Springer Nature 2021

\section{Correction to: Journal of Neurology}

https://doi.org/10.1007/s00415-020-10312-9

The original version of this article unfortunately contained a mistake. The correct information is given below.

Sixth author name on PubMed is listed as first name: "Ignacio" and last name: "Alvarez-Fernandez", when the preferred form should be first name: "Ignacio" and last name: "Alvarez".

Ignacio Alvarez's ORCID ID is: http://orcid. org/0000-0002-8537-3935

The original article can be found online at https://doi.org/10.1007/ s00415-020-10312-9.

Félix Javier Jiménez-Jiménez

fjavier.jimenez@salud.madrid.org; felix.jimenez@sen.es

1 Section of Neurology, Hospital Universitario del Sureste, Arganda del Rey, Madrid, Spain

2 University Institute of Molecular Pathology Biomarkers, UNEx, ARADyAL Instituto de Salud Carlos III, Cáceres, Spain

3 Fundació per la Recerça Biomèdica i Social Mútua de Terrassa, Terrassa, Barcelona, Spain

4 Movement Disorders Unit, Department of Neurology, Hospital Universitari Mutua de Terrassa, Terrassa, Barcelona, Spain

5 Section of Neurology, Hospital La Mancha-Centro, Alcázar de San Juan, Ciudad Real, Spain

6 Department of Medicine-Neurology, Hospital "Príncipe de Asturias", Universidad de Alcalá, Alcalá de Henares, Madrid, Spain 